\title{
ПРОИЗВОДСТВЕННО-ФИНАНСОВАЯ БЕЗОПАСНОСТЬ
}

УДК 332.122(1-772)

\section{О. А. Романова}

\section{НЕОИНДУСТРИАЛИЗАЦИЯ КАК ФАКТОР ПОВЫШЕНИЯ ЭКОНОМИЧЕСКОЙ БЕЗОПАСНОСТИ СТАРОПРОМЫШЛЕННЫХ РЕГИОНОВ ${ }^{1}$}

В статье на основании рассмотренных альтернативных иелей стратегического развития мировой экономики, связанных с формированием постиндустриального общества, финансиализаџией и неоиндустриализацией обосновано, что парадигмой развития мира ХХІ века является неоиндустриализация. Систематизированы предложения по движущим силам и механизмам ее осуществления. Показано, что на региональном уровне может быть успешно использован программно-иелевой подход как механизм неоиндустриализации экономики старопромышленного региона. Представлен конщептуальный подход к разработке Комплексной программы развития промылиленности в индустриальном регионе, реализующей идеи неоиндустриализации применительно $\kappa$ промышленности Свердловской области. Установлено, что региональные технологические платформы могут стать эффективным инструментом сочетания интересов территориального и отраслевого развития. Обосновано, что идея неоннустриализачии может быть реализована только при условии проведения продуманной промышленной политики и формирования дорожной карты движения к принципиально новой высокотехнологичной базе промышиленного развития. Актуализирована проблема формирования в прочессе неоиндустриализации «чистого» рынка как фактора повышения экономической безопасности.

Ключевые слова: постиндустриальная экономика, неоиндустриализация, механизмы, регион, комплексная программа, промышленность, безопасность

Глобализация мировой экономики потребовала пересмотра концептуальных подходов к развитию промышленности, сложившихся в последние десятилетия XX в. и выбору новых моделей экономического роста. В поисках таких моделей экономического роста и при неоднозначности стратегических приоритетов федерального уровня регионы формируют свои территориальные стратегии. В целях актуализации ранее разработанных стратегий регионального развития некоторые субъекты РФ разрабатывают программы развития важнейшего сектора региональной экономики - промышленности, во многом определяющей экономическую безопасность региона. Министерство промышленности и науки Свердловской области совместно с ИЭ УрО РАН формируют Комплексную программу

\footnotetext{
${ }^{1}$ Статья подготовлена при поддержке гранта РГНФ №1232-01021 «Ресурсный потенциал реиндустриализации старопромышленного региона».
}

развития промышленности Свердловской области на период 2012-2015 гг. и на период до 2020 года.

Применительно к проблеме развития промышленности как фактора обеспечения экономического благополучия и повышения экономической безопасности индустриальных регионов целесообразно отметить альтернативные цели стратегического развития мировой экономики: формирование постиндустриального общества, «финансиализация» как развитие качественно нового глобального экономического процесса, неоиндустриализация как парадигма развития мира XXI века.

Постиндустриальное общество. Среди принципиальных особенностей, свойственных экономике постиндустриального типа, можно выделить следующие: полное удовлетворение массовых жизненных потребностей населения и переход к их значительной дифференциации; 
снижение доли отраслей материального производства в ВВП; превращение сфер образования и науки в ключевые сферы национальной экономики; изменение сроков обновления материальных факторов производства и возрастного оборота рабочей силы и др. Указанные преобразования объединены главным признаком, каковым является повышение роли качественных сдвигов в развитии производства и общества.

В 80-х годах XX в. казалось неоспоримым мнение о полном превосходстве постиндустриальной экономики, о нахождении западным миром источника неограниченного богатства. Профессор Нью-Йоркского университета Пол Зейн Пилцер утверждал, что развитие индустриального производства требует использования минеральных, человеческих и материальных ресурсов, а в постиндустриальном мире ситуация другая. Создавая новые технологии, государства этого мира не тратят, а преумножают человеческий капитал, продавая технологии, они реализуют не сам продукт, а его копии, что не приводит к сокращению общественного достояния, а предопределяет неограниченность богатства постиндустриального мира.

С одной стороны, достижения стран с постиндустриальной экономикой бесспорны, с другой стороны, в этих странах сложилась неоднозначная ситуация. Произошло снижение доли обрабатывающей промышленности в ВВП до $10-13 \%$, резко возрос финансовый сектор, бюджет носит дефицитный характер, сохраняется устойчивым отрицательное сальдо внешней торговли. Появилась тенденция к снижению цен на технологии и высокотехнологичные товары. В итоге США, самая технологически развитая экономика мира, экспортирует технологий на 95 млрд долл. в год, что не превышает $0,65 \%$ ее ВВП [5]. В глобализированном мире производство технологий становится своего рода производством общественных благ, что экономически далеко не всегда оправдано с позиции стратегических приоритетов постиндустриальных стран. В то же время необходимо отметить, что на Западе во второй половине 1990-х годов термины, производные от понятия «постиндустриальное общество», использовались в 7-8 раз реже, чем в 1980-е годы. По мнению В. Иноземцева, сейчас этот термин воспринимается как простая банальность, как идея, которая вышла в тираж более 20 лет назад.
Однако в России по-прежнему акцентируется внимание на формировании постиндустриальной экономики. Справедливо отмечается, что формирование такой экономики - достаточно сложный и противоречивый процесс, разрабатываются предложения по развитию хозяйственного механизма, создающего условия перехода России к постиндустриальному обществу [9, с. 21], рассматриваются факторы экономического роста, наиболее значимые в условиях формирующейся в России, по мнению авторов $[10$, c. 40$]$, отмечается необходимость реструктуризации экономической и социальной сферы с целью приведения их «в соответствие с новой технологической базой и новой социальной структурой постиндустриального общества» [8, c. 12], то есть подчеркивается стратегическая ориентация на постиндустриальную экономику. Такие оценки представляются чрезмерно оптимистичными, не соответствующими реальной ситуации в России.

Развал плановой экономики, появление рыночных аспектов хозяйствования при отсутствии практического опыта участия в мировом рынке и неумении выделить приемлемые для российской экономики тенденции промышленного развития привели к ее деиндустриализации. Усугублению этого процесса способствовали разрыв межотраслевых связей, появление конкуренции на внутренних рынках между отечественной продукцией и импортными товарами. После крушения ослабленной экономической системы как России в целом, так и ее крупнейших промышленных регионов, деиндустриализация набирала ускоренные темпы. Кроме того, технологическое отставание отечественной гражданской промышленности, ее многолетнее исключение из мирового инновационного процесса привело к высокому уровню морального износа значительной части действующих производственных мощностей, повышенной ресурсои энергоемкости производства, экологической перегруженности территорий базирования промышленных предприятий.

Все это подтверждает тот факт, что Россия не преодолела необходимого этапа индустриального развития, который прошли западные страны и не может ориентироваться на постиндустриальную экономику.

Финансиализация. При обосновании новой модели экономического роста рассматривается возможность финансиализации, то есть качест- 
венно нового глобального экономического процесса, в рамках которого происходит существенное сближение функционирования фондового, валютного и товарного рынков, усиление их взаимовлияния, активизация переливания капитала между указанными рынками. Некоторыми авторами финансиализация России рассматривается как «создание собственного эффективного финансового сектора» [13, с. 11]. Под «стратегией финансиализации» в данном случае понимается аккумулирование рентных и других доходов, формирование финансовых рынков и институтов, внедрение финансовых инструментов. Все это должно способствовать переводу накопленных сбережений в инвестиции по организации высокотехнологичного производства конкурентной готовой продукции.

Преимуществом «стратегии финансиализации» является продолжение рыночных преобразований, усиление либеральной модели экономики. Однако сама возможность переориентации отечественной экономики на выпуск готовой продукции является достаточной проблематичной, ибо сам по себе рынок в условиях открытости экономики не определяет крупные структурные сдвиги. Реализация «стратегии финансиализации» не позволит России не только занять достоянное место среди развитых стран, но и остановить процессы деиндустриализации экономики.

Неоиндустриализация. Реализация в России экспотрно-сырьевой модели развития привела к тому, что движение в постиндустриальную эру обошло Россию стороной. Стремительный рост доли сырьевой экономики и снижение доли промышленного производства способствовали возврату России в доиндустриальное прошлое. В отечественной экономике очень слаба промышленная база, способная потреблять знания и создавать на их основе инновации, проблематично быстрое развитие высокотехнологичного сектора экономики.

В этих условиях очень важен учет успешного опыта реиндустриализации экономики европейских стран [2], которая, так же как и экономика США, объективно переросла промышленность в традиционном ее понимании и не вернется к старому индустриализму. Но ценный опыт не столько развития постиндустриальной экономики, сколько опыт реиндустриализации должен быть внимательно изучен в процессе разработки политики восстановления отечественной индустрии при обязательном условии учета национальных особенностей и реальных возможностей реиндустриализации. Можно отметить, что даже в развитых странах Европы национальные модели реиндустриализации имеют значительные отличия. Так, во Франции индустриальное развитие остается приоритетным и широко применяется стратегия государственного регулирования и поддержки крупных проектов. В Германии промышленная политика проводится через земли (аналоги отечественных регионов). Здесь проводится активная политика развития территорий, которая предполагает субсидирование промышленности и основополагающую роль банков в поддержке промышленности. Такое разнообразие подходов нивелируется в рамках ЕС за счет разработки общих принципов промышленной политики Европы. Начиная с 2000 года, в Европе реализуется практика разработки технологических платформ, признаваемых важнейшим инструментом «промышленной политики расширившейся Европы».

Стратегия стран Западной Европы определила не переход к постиндустриальному обществу, а скорее к возрождению на новых технологических основаниях современной промышленности. Здесь основная цель развития не была связана с массовостью производства продукции, а предопределяла важность производства предметов индивидуализированного потребления. То есть в этих странах не произошло отказа от индустрии, но это новая индустрия, где на передовом технологическом уровне максимизируется добавленная стоимость на индивидуализации потребления. Таким образом, ЕС, в отличие от Америки, не отказывается от индустрии (здесь доля промышленности в ВВП в 2-3 раза выше, чем в США), а проводит политику ее индивидуализации и реиндустриализации.

В целом ряде работ подчеркивается ошибочность стратегии деиндустриализации экономики России и обосновывается предпочтительность неоиндустриальной парадигмы как единственно возможного эффективного развития отечественного производства. Формула такого развития, по мнению С. Губанова, предполагает «неоиндустриализацию плюс вертикальную интеграцию» [3]. Проведение новой индустриализации как объективно назревшего процесса подчеркивается в качестве стратегического приоритета развития экономики России и в других работах [13, с. 17]. Наличие необходимых предпосылок 
и основополагающие принципы еe проведения обоснованы в докладе «Деловой России» $[11$, с. 78-79]. Заложенные здесь идеи получили развитие в «Стратегии $25 \times 25 »$, в которой ключевым фактором является модернизация экономики по кластерным принципам и заявлена амбициозная цель - создать к 2025 г. 25 млн новых высокопроизводительных рабочих мест. В Стратегии обосновано, что только современный развитый индустриальный сектор может обеспечить быстрый и качественный рост экономики. Объясняется это тем, что из всех секторов именно промышленность обеспечивает наиболее высокие темпы роста производительности труда и оказывает высокий мультипликативный эффект на другие сектора экономики.

При всей привлекательности задачи создания такого количества высокопроизводительных рабочих мест нельзя не учитывать, что современный уровень технической вооруженности рабочего места в России не сопоставим с аналогичными показателями развитых стран. Фондовооруженность рабочего места в отечественной обрабатывающей индустрии составляет всего 14,4\% аналогичного американского показателя, в добывающей промышленности 15,2\%. По экспертным оценкам, для достижения требуемой фондовооруженности рабочего места в добывающую промышленность России необходимо вложить 540 млрд долл., в обрабатывающую 988 млрд долл., то есть всего более 1,5 трлн долл. [1, с. 38] В то же время инвестиции в России не превышают 60 млрд долл. в год, что, применительно к обрабатывающей промышленности, можно сравнить с требуемыми 16-17 годовыми инвестиционными бюджетами для получения сопоставимых с американскими показателями фондовооруженности труда.

В соответствии со «Стратегией $25 \times 25 »$, роль государства в создании новых рабочих мест состоит в создании условий и оказании инвесторам системной поддержки. В то же время известен опыт европейских стран, когда инвестору выделяют субсидии за создание рабочих мест. Так, в Германии в традиционных промышленных отраслях за каждое новое рабочее место выдают до 125 тыс. евро, но не более $25 \%$ от инвестиций. В среднем это рабочее место приносит 30 тыс. евро налогов, то есть срок окупаемости бюджетных инвестиций - 4 года $[15$, с. 52$]$. Можно отметить, что в России фактически в последние годы не создавались новые рабочие места, а эконо- мика продолжала уходить в тень. Если в 2001 г. в организациях всех видов было занято 51, 2 млн человек, то к 2011 г. - около 46 млн. К 2011 г. в неформальном секторе работало примерно от 20 до $30 \%$ всех занятых, что значительно больше, чем в развитых странах $[14$, с. 22]. Эти данные вызывают серьезные опасения с позиции экономической безопасности, ибо рост численности занятых в неформальном секторе экономики, отличающемся низкой производительностью и использованием примитивных технологий, приводит к упрощению производства и снижению мотивации к неоиндустриализации.

Экономика России в последние годы демонстрирует достаточно уверенный рост, поддерживаемый высокими ценами на нефть. Объем ВВП в конце 2011 года вернулся к докризисному максимуму при уверенном росте потребления. В 2011 г. Россия заняла 9 место в мире по объему ВВП. В 2007 г. она занимала 11 место по этому показателю. При расчете ВВП по паритету покупательной способности российская экономика находится на 6 месте в мире. Инфляция достигла самого низкого уровня за последние 20 лет. В 2011 г. государственный долг составил не более 10\% ВВП, тогда как в наиболее развитых странах средний уровень государственного долга превысил 100\% ВВП [7, с. 5]. Однако преобладающая часть таких впечатляющих успехов достигнута на базе высоких цен на нефть. Можно отметить, что ненефтяной дефицит бюджета сохраняется на уровне, близком к 10\% ВВП.

Снижение зависимости развития экономики России от мировой конъюнктуры предполагает построение сбалансированной и гармоничной экономики, что может быть достигнуто при проведении ее диверсификации. В этом случае экспортоориентированная модель экономического роста должна быть переориентирована на активизацию внутренних источников развития и поддержку экспорта высокотехнологичных товаров и услуг. Реальная диверсификация экономики России как ключевой пункт ее стратегического развития возможна только при условии превращения сырьевого сектора в опорную базу структурных изменений в отечественной экономике. Политика диверсификации предполагает повышение эффективности системы государственного управления. Опыт ряда стран показывает, что она может быть сориентирована на обеспечение народнохозяйственных интересов. Но для достижения этой цели недостаточно ис- 
пользования контроля со стороны государства, нужен действенный контроль со стороны общества за принимаемые решения, используемые ресурсы, прежде всего - бюджетные средства.

Структурные преобразования не могут быть осуществлены как стремительное становление нового высокотехнологического качества экономики. Это поэтапный и долгосрочный процесс, предполагающий не только последовательно реализуемую систему действий, но и реальную перестройку интересов власти и бизнеса. Эти интересы должны быть перенаправлены от обслуживания экспортно-сырьевого сектора экономики на общенациональные интересы сбалансированного развития всей экономики.

Наиболее активные дискуссии сейчас проводятся о возможностях реализации при проведении реальной экономической политики системы взглядов, характерных для неоиндустриальной экономики. Становление инновационного типа развития зачастую трактуется как создание новых предприятий и новых секторов хозяйства, формирующих в совокупности так называемую «новую экономику», характеризующуюся производством наукоемкой и высокотехнологичной продукции. В то же время значительно меньше внимания уделяется модернизации традиционных индустриальных отраслей, где происходит устаревание технологий, повышение до недопустимых пределов износа оборудования, то есть снижение эффективности производства, минимизация финансовых источников для социально-экономического развития страны и структурной перестройки ее экономики.

Применительно к экономике страны в целом, и ее старопромышленным регионам в частности, представляется обоснованным говорить о развитии инновационного сектора не только на основе вытеснения традиционных отраслей экономики, но и на основе технико-технологического обновления этих отраслей и производств с приданием профильным отраслям высокотехнологичного и наукоемкого облика. Переход к новым техникотехнологическим основаниям, выход промышленного производства на новые прогрессивные уровни развития определяют неоиндустриализацию как актуальный тренд современного этапа экономического развития страны и ее старопромышленных регионов.

Движущцие силы и механизмы осуществления неоиндустриализации. Вопрос об определении движущей силы неоиндустриализации активно обсуждается в научной литературе. В работах С. Губанова рассматриваются такие альтернативные силы, как государство и частный капитал, то есть система свободной конкуренции при безусловном предпочтении главенствующей роли государства. Им обосновано предложение о формировании вертикально интегрированного строения экономики для создания государственно-корпоративного сектора в качестве ядра системы общественного воспроизводства. Высказывается более чем спорное, по нашему мнению, предложение о переходе к политике неоиндустриализации путем формирования общегосударственного плана национализации стратегических объектов экономики, вертикальной интеграции и накопления внутреннего фонда неоиндустриализации [3, с. 19]. По мнению В. Рязанова, в качестве главной движущей силы неоиндустриализации выступает государство при вспомогательной роли рыночных отношений. Кроме того, при проведении неоиндустриализации экспортно-ориентированная модель экономического роста должна быть переориентирована на активизацию внутренних источников развития. Это предполагает более жесткий контроль за внешнеэкономическими отношениями, регулирование движения капитала и т. д. [13, с. 15]

В отличие от взглядов ряда специалистов на понимание государства как движущей силы неоиндустриализации, представители «Деловой России» воспринимают государство как субъект стимулирования и регулирования свободного рынка. Проведение неоиндустриализации возможно только при условии создания действенного механизма, реализующего непротиворечивые цели при ее осуществлении на федеральном и региональном уровнях. Представители «Деловой России» признают целесообразность для проведения особой политики неоиндустриализации создание специального государственного органа, ответственного за ее проведение и наделенного достаточно высокими полномочиями с целью концентрации ресурсов в тех секторах, развитие которых позволит получить наибольший мультипликативный эффект.

Подобный подходу «Деловой России» подход к созданию необходимых новых институциональных структур для проведения неоиндустриализации экономики России демонстрирует С. Губанов, который предлагает в составе высших органов исполнительной власти учредить 
федеральное агентство по планированию неоиндустриального развития России [3, с. 20].

Разработка специальной программы проведения новой индустриализации экономики России, целью которой является создание сбалансированной, гармоничной, независимой от внешнего влияния отечественной экономики, предлагается В. Рязановым [13, с. 17]. По его мнению, целесообразно аккумулировать часть средств фонда национального благосостояния на специальном инновационно-инвестиционном фонде как внебюджетном фонде. Назначение такого фонда - поддержка внутренних институтов развития через организацию софинансирования наукоемких производств, перспективных научно-технических разработок, экологических программ и т. д. Формирование совета и контроль за его деятельностью предлагается осуществлять законодательной властью.

Комплексная программа развития промышленности Свердловской области на 20122015 z2, и на период до 2020 г. В мировой экономике все больше распространяются модели развития, для которых территории не являются пассивным пространством, принимающим филиалы крупных корпораций. Они способны создавать специфические ресурсы, развивать инновационную деятельность и создавать конкурентные преимущества путем объединения в территориальные комплексы. Выигрывают те регионы, где в результате эффективной политики по обустройству территории создается обстановка привлекательности для бизнеса. Рынки сбыта промышленной продукции утрачивают национальные или локальные черты, поскольку торговая интеграция приобрела мировой масштаб. Выход на мировой рынок отдельным предприятиям затруднен, что предполагает развитие интеграционных процессов на территории. Появилась концепция интернационализирующей среды, введенная в обиход для обозначение факторов, связывающих динамику местной предпринимательской сети с динамикой мировой экономики. Эта среда должна обладать эффективной инфраструктурой, обеспечивая качественные условия жизни. Плотность предприятий, сертифицированных по стандартам ISO, является количественным и качественным показателем интернационализирующего характера той или иной среды [2, с. 39].

Все большее число исследователей говорят о целесообразности разработки такой страте- гии экономического развития, основу которой должно составить структурно сбалансированое развитие экономики, при оптимальном взаимодействии всех секторов реальной экономики, в первую очередь, минерально-сырьевого и обрабатывающего. Появились предложения о формировании интегрированной ресурсно-перерабатывающей модели [6]. Модель интегрированного взаимодополняющего функционирования минерально-сырьевого и промышленно-перерабатывающего секторов применима, прежде всего, в тех регионах, для которых освоение минерально-сырьевой базы и создание на ее основе индустриально-технологического минеральносырьевого комплекса являются приоритетами развития экономики.

Именно таким регионом является Средний Урал. Здесь может быть реализована ресурсноперерабатывающая стратегия развития, базирующаяся на высоком производственном потенциале региона, богатстве его недр, наличии разнообразных месторождений полезных ископаемых, включая техногенные ресурсы, эффективная добыча и переработка которых может быть использована не только для неоиндустриализации российской экономики, но и для взаимовыгодного международного сотрудничества со странами, бедными минеральным сырьем [12].

Как было отмечено выше, Министерством промышленности и науки Свердловской области совместно с ИЭ УрО РАН разрабатывается «Комплексная программа развития промышленности Свердловской области на 2012-2015 гг., и на период до 2020 г.». В последние годы промышленность области развивалась достаточно успешно. Если по России индекс промышленного производства составил в 2011 г. 104,7\% к 2010 г., то в Свердловской области - 105,5\%. Объем отгруженной промышленной продукции в области возрос на $24,1 \%$. Сальдированный финансовый результат по обрабатывающим производствам составил 98,1\% к 2010 г. Удельный вес убыточных организаций по такому виду деятельности, как добыча полезных ископаемых, составил $18,5 \%$ (при $31 \%$ в Челябинской области и $33,3 \%$ в Пермском крае). По обрабатывающим производствам удельный вес убыточных организаций в Свердловской области - 27,3\% (в Челябинской области - 29,8\%, в Пермском крае - 31,7\%). Среднемесячная начисленная заработная плата в расчете на одного работника 
составила по обрабатывающим производствам в Свердловской области 23,2 тыс. руб., что выше аналогичного показателя всех субъектов РФ, входящих в Большой Урал. Выше данного показателя только среднемесячная заработная плата по Тюменской области.

Разработка «Комплексной программы развития промышленности Свердловской области на 2012-2015 гг., и на период до 2020 г.» не может быть проведена как простое уточнение позиций, заложенных в «Стратегии социально-экономического развития Свердловской области на период до 2020». Обязательность достижения темпов роста ВВП, роста физических объемов производства, заложенных в качестве индикаторов развития экономики области, сегодня не является определяющей. Критичный фактор в предстоящие годы - это предоставление более интересной, творческой работы, широкие возможности профессионального роста, что возможно только на основе повышения технологического уровня промышленности Свердловской области. В качестве общенациональной задачи, вокруг решения которой, очевидно, будет строиться государственная политика, консолидироваться усилия бизнеса, власти и науки является задача создания 25 млн новых высокотехнологичных хорошо оплачиваемых рабочих мест.

Основной идеей Программы является формирование нового технологического облика промышленности Свердловской области. Для этого важно не только выявить тенденции мирового, национального и регионального промышленного развития, но и оценить возможности стратегической устойчивости развития промышленности региона за счет собственных доходных источников в интересах реализации как макрои мезоэкономических целей, так и внутрирегиональных приоритетов.

Возможность достижения нового технологического облика промышленности области во многом будет определяться уровнем инновационности новых технологических решений. К настоящему времени можно отметить повышение инновационной активности промышленных предприятий. Так, по данным исследования фонда «Петербургская политика» в 2011 г. Свердловская область наряду с Томской областью и Подмосковьем признана одной из ведущих инновационных территорий России. Аналитики Forbes заявили о том, что Свердловская область находится на втором месте в списке 30 лучших регионов страны для ведения бизнеса. В то же время, очевидно, что без участия государства в решении ключевых задач инфраструктурного, инвестиционного и инновационного характера промышленность не сможет выйти на необходимый уровень конкурентоспособности и обеспечить реализацию конкурентных преимуществ на внешнем и внутреннем рынках. Для выведения промышленности как важнейшего сектора экономики на современный технологический, экономический и управленческий уровень органы государственной власти должны сформировать политику, определяющую национальные цели и приоритеты промышленного развития, сформировать инструменты их реализации.

В разрабатываемой Программе в соответствии с проектом Государственной программы «Развитие промышленности и повышение ее конкурентоспособности» определены 4 блока отраслей, для каждого из которых предусматриваются специфичные инструменты регулирования развития. Для первого блока — предприятий металлургической и химической промышленности - ситуация, определяемая конъюнктурой мировых рынков, складывается относительно благополучно, что не исключает возможных рисков. Основные меры регулирования развития этих отраслей предусматривают содействие организации углубленной переработки сырья, выпуску конечных видов продукции с ориентацией не только на мировой, но и на внутренний рынок.

Для второго блока - производств, ориентированных на развитие локальных рынков (машиностроение, легкая и лесная промышленность, дорожно-строительная техника и др.) - предполагается содействие их включению в глобальные цепочки, ориентация на импортозамещение, поддержка инфраструктурных проектов. Для этих отраслей, ориентированных на локальный спрос, необходима ориентация на выход в дальнейшем на мировые рынки, что требует приоритетного привлечения инвестиций для технологической модернизации. К третьему блоку относятся отрасли с доминирующим государственным участием, прежде всего, это оборонно-промышленный комплекс. Регулирование развития данного комплекса предполагает, главным образом, использование инструментов и мер поддержки федерального уровня. Однако в Программе предусматриваются необходимые меры содействия развитию гражданского про- 
изводства на данных предприятиях. Развитие некоторых особо важных с позиции диверсификации и социальной значимости высокотехнологичных производств, например, фармацевтической промышленности, является предметом самостоятельных программных документов.

В Программе особое внимание обращается на территориальный аспект промышленного развития. В территориальном разделе программы выделяются промышленно ориентированные муниципальные образования Свердловской области, определяется пространственная конфигурация промышленного комплекса области, проводится институциональный анализ форм территориальной организации промышленного производства. Центральным аспектом территориального развития промышленности является кластерная политика Свердловской области. Здесь могут быть созданы кластеры в машиностроительной, металлургической, химической, фармацевтической, ИТ-отраслях, в области переработки техногенных отходов и др. Создаваемая особая экономическая зона «Титановая долина» на первоначальном этапе своего развития будет функционировать как кластер. Под Верхней Салдой сосредоточится производство и обработка титана для нужд автопрома, судо- и самолетостроения, и космонавтики. Затем в состав зоны могут войти высокотехнологичные компании из химической, фармацевтической, деревообрабатывающей и других отраслей. в особой экономической зоне будет 65 резидентов, способных инвестировать в свое предприятие не менее 3 млн евро [4, с. 24].

Особое значение в неоиндустриализации экономики Урала имеет развитие высокотехнологичных производств, связанных с использованием редкоземельных металлов. Редкоземельные металлы, которые называют элементами будущего, имеют стратегическое значение для экономики страны. Они являются незаменимыми составляющими производства самых разнообразных высокотехнологичных продуктов. Можно отметить, что Россия по запасам редкоземельных металлов занимает второе место в мире, уступая лишь Китаю, однако на мировом рынке ее доля составляет менее $2 \%$ при 97\% доли Китая. Среди российских регионов, где имеются реальные предпосылки воссоздания редкоземельной отрасли, разрушенной после распада СССР, наиболее благоприятные условия имеет Урал. Он располагает достаточно большой сырьевой базой для получения редких и редкоземельных металлов. Кроме того, именно на Урале создан мощный промышленный комплекс, где расположены как предприятия по переработке техногенных запасов сырья (ОАО «Уральский электрохимический комбинат», предприятие «Маяк» и др.), так и предприятия, непосредственно производящие редкоземельную продукцию (Соликамский магниевый завод, Уралредмет, Ключевской завод ферросплавов и др.).

На Урале также расположены многочисленные потребители редкоземельной продукции. Прежде всего, это предприятия оборонной промышленности, металлургии, химической промышленности, машиностроения. Важным фактором, определяющим целесообразность развития редкоземельной отрасли на Урале, является возможность квалифицированного научного сопровождения процессов технологического развития. Здесь сосредоточены ведущие институты РАН, которые занимаются проблемами редкоземельных металлов, создана ассоциация разработчиков и потребителей постоянных магнитов - наиболее значимых потребителей редкоземельных металлов. Все вышесказанное позволяет считать целесообразным создание на Урале редкоземельного кластера по получению и применению редкоземельных элементов. В настоящее время с участием Института экономики УрО РАН и Министерства промышленности и науки Свердловской области формируется концепция вышеотмеченного кластера. Его создание будет способствовать росту региональной конкурентоспособности, повысит инвестиционную привлекательность региона, позволит выйти на международный рынок высокотехнологичной продукции.

Особое значение для формирования высокотехнологичных производств, на базе которых возможно преобразование экономики старопромышленного региона в современную инновационную конкурентоспособную экономику, может сыграть фотоника как чрезвычайно перспективное направление, все условия для развития которого имеются на Урале. Нанотехнологии без фотоники неосуществимы. Использование достижений фотоники в промышленности, в частности, в металлургии, в таких производствах, как резка, сварка, термообработка, полировка, маркировка, позволяет повысить гибкость и конкурентоспособность промышленной продукции при росте производительности труда в 10-15 раз. 
Развитие квантовой металлургии и плазмохимии может позволить, по оценке главного конструктора-директора ООО Уральское научнопроизводственное предприятие «ЛАЗЕР» С. П. Пенкина, поднять производительность существующих металлургических производств на принципиально другой уровень. Предварительные исследования свидетельствуют о возможности создания Уральского центра фотоники и целесообразности разработки специальной программы развития фотоники в области машиностроения, металлургии, плазмохимии, переработки промышленных отходов, с выделением специального блока по подготовке требуемых специалистов.

Значительное внимание в Программе уделяется такому относительно новому инструменту регулирования промышленного развития, как технологические платформы (ТП). Сформировано около 30 федеральных технологических платформ, перечень которых утвержден решением Правительственной комиссии по высоким технологиям и инновациям (апрель 2011 г.). Они рассматриваются как площадка для коммуникационных взаимодействий бизнеса, государства, науки, гражданского общества для создания перспективных коммерческих технологий, новых продуктов, для привлечения дополнительных ресурсов, для проведения исследований и разработок на основе участия всех заинтересованных сторон, для совершенствования нормативно-правовой базы в области научнотехнологического инновационного развития.

В рамках ТП федерального уровня «Твердые полезные ископаемые» участвуют Институт горного дела УрО РАН и Уральский государственный горный университет. В рамках федеральной ТП «Новые полимерные композиционные материалы и технологии» предложена региональная ТП УрО РАН «Новые материалы и технологии специального назначения». Основная цель данной программы - разработка и производство новых материалов и технологий, их передача российским промышленным предприятиям, работающим в области высокотехнологичного сектора экономики. Обоснованы этапы разработки и определены требуемые объемы финансирования для выпуска материалов и технологий специального назначения: новые магнитные материалы для современной промышленности и наноиндустрии; безопасные высокоэнергетические материалы; новые металлические и нанокомпозитные материалы, специальные покрытия для использования в экстремальных условиях, в том числе для аэрокосмической и ядерной техники; материалы и технологии для альтернативной энергетики; материалы и технологии получения порошковых, композиционных, полимерных и керамических наноматериалов; уникальные приборы и устройства для сильноточной импульсной электроники. В качестве потенциальных исполнителей проектов определены институты УрО РАН.

На базе институтов УрО РАН формируется проект региональной технологической платформы в области горно-металлургического комплекса «Инновационное развитие горно-металлургического комплекса Урала». В рамках ТП предполагается развитие инновационных технологий в области: технологий ускоренной разведки месторождений, добычи, переработки и обогащения природного сырья; технологий комплексной переработки руд черных и цветных металлов; технологий комплексной переработки, утилизации отходов горно-металлургических производств, нейтрализации и очистки воды, рекультивация земель; разработки горно-металлургического оборудования и геофизических приборов и методов.

Объединение усилий бизнеса, академической, отраслевой и вузовской науки, общественных организаций при координации всей деятельности со стороны региональных органов власти будет способствовать обновлению научно-производственной и опытно-конструкторской базы горно-металлургического комплекса Урала; повышению технологической конкурентоспособности, энергоэффективности и экологической безопасности в горно-металлургическом комплексе; активизации инновационной деятельности горно-металлургического сектора экономики в направлении организации выпуска продукции с высокими потребительскими свойствами для обеспечения потребностей машиностроения, строительства и других секторов экономики.

Переживаемый сегодня мировой экономикой системный кризис является реальным проявлением длительного перехода в новую экономическую, технологическую, геополитическую эпоху, эпоху турбулентности и непредсказуемости развития. Принятие решения о вступлении России в ВТО, неизбежность формирования нового технологического уклада предопределили не- 
обходимость учета в Программе возможности реализации «концепции управляемого сжатия» с одной стороны, и «концепции полюсов конкурентоспособности» - с другой. В рамках концепции управляемого сжатия делаются прогнозные оценки по обоснованию подотраслей или отдельных предприятий, применительно к которым неэффективной может оказаться господдержка и в отношении которых целесообразно принять меры по своевременному сворачиванию производства с ориентировочной оценкой требуемых для этой цели затрат. Одновременно проводится обоснование перспективных полюсов конкурентоспособности как совокупности предприятий, потенциал которых по выпуску конкурентоспособной не только на региональном, но и на мировом рынке продукции значительно превышает средние показатели по территории Свердловской области.

Анализ выявленных тенденций промышленного развития показал устойчивую тенденцию роста государственных расходов на развитие промышленности с применением соответствующих протекционистских мер в отношении отечественных производителей. В России появляются необходимые условия для перерас- пределения приоритетов развития экономики из сырьевого сектора в направлении развития высокотехнологичного производства товаров и услуг. Это выдвигает особые требования к формированию промышленной политики, реализующей единую как на федеральном, так и на региональном уровнях стратегическую цель неоиндустриализацию экономики. Идея неоиндустриализации должна превратиться в продуманную промышленную политику, в дорожную карту движения к принципиальной новой промышленной основе, реализующей мировые технологические достижения с учетом особенностей индустриальных регионов России. Расширение высокотехнологичных площадок будет притягивать к себе креативные кадры, заинтересованные в прозрачном бизнесе. Жесткие правила на инновационном рынке формируются потому, что сама логика высокотехнологичного производства требует прозрачности сделок, своевременной уплаты налогов и исключает коррупцию. Формирование в процессе неоиндустриализации чистого рынка, которое уже начинается в России, явится серьезным фактором повышения экономической безопасности.

\section{Список источников}

1. Алексеев А. Новая индустриализация: оценка потребности в накоплении // Экономист. -2012. - №12. - С. 29-41

2. Бландиньер Ж.-П. Реиндустриализация России. Насколько пригоден европейский опыт // Экономист. - 2005. №5. - С. 35-45.

3. Губанов С. К политике неоиндустриализации России // Экономист. - 2009. - №9. - С. 20.

4. Дружинин С. Нерыночные инновации // Деловой квартал. - 2012. — №13. - С. 24.

5. Иноземцев В. Воссоздание индустриального мира // Россия в глобальной политике. $-2011 .-14$ дек.

6. Кимельман С. Интегрированная ресурсно-перерабатывающая модель // Экономист. — 2012. — №1. - С. 11-23.

7. Кузнециов И. Нам так и не снилось в ВТО // Экономика и жизнь. - 2012. - №12. (30 март). - С. 5.

8. Мау В. Экономика и политика в 2011 году. Глобальный кризис и поиск новой модели роста // Вопросы экономики. - 2012. - №2. - С. 4-27.

9. Михайлов А. М. Реализация экономических и институциональных интересов собственников факторов производства : автореф. дисс. ... д-ра экон. наук. - Самара, 2009.

10. Орлова Т.С., Конюховский Е.П. Трансформация факторов экономического роста в условиях глобальной экономики // Вестник Челябинского государственного университета. 2011. №36. Экономика. вып. 35. С. 39-46

11. От эксплуатации сырьевой модели и новой индустриализации / Голубович А., Идрисов А., Иноземцев В., Титов Б, Шпиглем М. // Общество и экономика. - 2009. - №7. - С. 46-87

12. Романова О.А. Условия и факторы структурной модернизации региональной промышленной системы // Экономика региона. 2011. №2. С. 40-49.

13. Рязанов В. От рентной экономики к новой индустриализации России // Экономист. — 2011. — №8. - С. 11-17.

14. Титов Д., Санжиев Д. Стратегия 2020 // Экономика и жизнь. - 23 марта 2012. №11 (23 марта). - С. 22.

15. Яковенко Д. Промышленность в новом формате // Эксперт. - 2011. - №43. - С. 52.

\section{Сведения об авторе}

Романова Ольга Александровна (Екатеринбург) - доктор экономических наук, профессор, руководитель отдела региональной промышленной политики и экономической безопасности, Институт экономики Уральского отделения Российской академии наук (620014, г. Екатеринбург, ул. Московская, 29, e-mail: econ@uran.ru). 
O. A. Romanova

\section{Neoindustrialization as a factor in improving economic security of old-industrial regions ${ }^{1}$}

This paper proves that the paradigm of the world of the XXI century is neoindustrialization on the basis of alternative strategic goals of the global economy associated with the formation of post-industrial society and financialization neoindustrialization. A systematic proposal for the driving forces and mechanisms for its implementation is suggested. It is shown that target-oriented approach can be successfully used at the regional level as a mechanism for economic neoindustrialization of an old-industrial region. Conceptual approach to developing comprehensive program of industrial development in the industrial region that implements the ideas of neoindustrialization in relation to industry of Sverdlovsk region is presented.

It was found that the regional technology platform can be an effective tool for combining the interests of territorial and sectoral development. It is proved that the idea of neoindustrialization can be realized only as a result of wise industrial policy and road map formation for the movement to an entirely new high-tech based industrial development. In the process of forming, the problem of neoindustrialization of a "pure» market as a factor in increasing the economic security is actualized.

Keywords: post-industrial economy, neoindustrialization, mechanisms, region, comprehensive program, industry, security

\section{References}

1. Alekseev A. (2012). Novaya industrializatsiya: otsenka potrebnosti v nakoplenii [New industrialization: assessment of the accumulation needs]. Ekonomist [Economist], 12, 29-41.

2. Blandin'er Zh.-P. (2005). Reindustrializatsiya Rossii. Naskol'ko prigoden evropeyskiy opyt [Re-industrialization of Russia. How suitable is the European experience]. Ekonomist [Economist], 5, 35-45.

3. Gubanov S. (2009). K politike neoindustrializatsii Rossii [On the policy of Russia's neoindustrialization]. Ekonomist [Economist], 9, 20.

4. Druzhinin S. (2012). Nerynochnye innovatsii [Non-market innovations]. Delovoy kvartal [Business Qaurter], 13, 24.

5. Inozemtsev V. (2011, December 14). Vossozdanie industrial'nogo mira [Reconstruction of the industrial world]. Rossiya $\mathrm{v}$ global'noy politike [Russia in global politics].

6. Kimel'man S. (2012). Integrirovannaya resursno-pererabatyvayushchaya model' [Integrated resource-processing model]. Ekonomist [Economist], 1, 11-23.

7. Kuznetsov I. (2012, March 30). Nam tak i ne snilos' v VTO [We've never dreamed of in the WTO]. Ekonomika i zhizn' [Economics and Life], 12, 5.

8. Mau V. (2012). Ekonomika i politika v 2011 godu. Global'nyy krizis i poisk novoy modeli rosta [Economics and politics in 2011. The global crisis and the search for a new growth model]. Voprosy ekonomiki [Questions of Economics], 2, 4-27.

9. Mikhaylov A. M. (2009). Realizatsiya ekonomicheskikh i institutsional'nykh interesov sobstvennikov faktorov proizvodstva: avtoref. diss. ... d-ra ekon. nauk [Implementation of economic and institutional interests of the owners of production factors. Synopsis of a $\mathrm{PhD}$ thesis]. Samara.

10. Orlova T.S., Konyukhovskiy E.P. (2011). Transformatsiya faktorov ekonomicheskogo rosta v usloviyakh global'noy ekonomiki [Transformation of growth factors in the global economy]. Vestnik Chelyabinskogo gosudarstvennogo universiteta [Bullettin of Chelyabinsk State University], 36, Economics, Issue ,35, 39-46.

11. Golubovich A., Idrisov A., Inozemtsev V., Titov B, Shpiglem M. (2009). Ot ekspluatatsii syr'evoy modeli i novoy industrializatsii [From the exploitation of raw materials model and a new industrialization]. Obshchestvo i ekonomika [Society and Economics], 7, 46-87.

12. Romanova O.A. (2011). Usloviya i faktory strukturnoy modernizatsii regional'noy promyshlennoy sistemy [Conditions and factors of structural modernization of a regional industrial system]. Ekonomika regiona [Economy of Region], 2, 40-49.

13. Ryazanov V. (2011). Ot rentnoy ekonomiki k novoy industrializatsii Rossii [From the rent economy to the new industrialization of Russia]. Ekonomist [Economist], 8, 11-17.

14. Titov D., Sanzhiev D. (2012, March 23). Strategiya 2020 [Strategy 2020]. Ekonomika i zhizn' [Economics and Life], 11, 22.

15. Yakovenko D. (2011). Promyshlennost' v novom formate [Industry in a new format]. Ekspert [Expert], 43, 52.

\section{Information about the author}

Romanova Ol'ga Aleksandrovna (Yekaterinburg, Russia) - Doctor of Economics, Professor, Head of the Department for Regional Industrial Policy and Economic Security, Institute of Economics, Ural Branch of the Russian Academy of Sciences (620014, Yekaterinburg, Moskovskayast., 29, e-mail: econ@uran.ru).

\footnotetext{
${ }^{1}$ This paper was written with financial support of a grant by Russian Humanitarian Science Foundation, project number 12-3201021, Reindustrialization of an old-industrial region.
} 